\title{
Avaliação da apoptose de leucócitos polimorfonucleares CH138+ em leite bovino de alta e baixa contagem de células somáticas - dados preliminares
}

\author{
[Polymorphonuclear leukocytes CH138+ apoptosis evaluation in milk with high and low \\ somatic cell count - preliminary data] \\ R.B. Pessoa, M.G. Blagitz, C.F. Batista, B.P. Santos, A.C. Parra, F.N. Souza, \\ A.M.M.P. Della Libera* \\ Faculdade de Medicina Veterinária e Zootecnia - Universidade de São Paulo \\ (FMVZ-USP) - São Paulo, SP
}

\begin{abstract}
RESUMO
A apoptose de leucócitos polimorfonucleares (PMN) é um evento central no processo de resolução da inflamação. Sendo a contagem de células somáticas (CCS) um indicador da situação imunológica da glândula mamária, o presente estudo buscou esclarecer a influência que esses fatores têm um sobre o outro e sobre a evolução do processo inflamatório. Marcaram-se as amostras de leite com anexina-V, iodeto de propídeo (PI), anticorpo anti-CH138A. Encontrou-se correlação negativa entre apoptose de PMN e CCS, além de diferença estatística entre um grupo de alta CCS e um grupo de baixa CCS quanto à taxa de PMN viáveis, em apoptose, em necrose e em necrose e/ou apoptose. De modo geral, o grupo de alta celularidade apresentou menos $\mathrm{CH} 138+$ em apoptose e mais células em necrose ou viáveis do que o grupo de baixa celularidade. Conclui-se que apoptose de PMN e CCS estão relacionados, e que em mamas com CCS elevada este evento está diminuído. Apesar de haver maior disponibilidade de fagócitos para a defesa nessa situação, os efeitos anti-inflamatórios da apoptose também estão diminuídos, enquanto os efeitos pró-inflamatórios da necrose estão aumentados, o que pode colaborar com a cronificação da inflamação.
\end{abstract}

Palavras-chave: apoptose, $\mathrm{CH} 138 \mathrm{~A}$, citometria de fluxo, bovinos, leite

\begin{abstract}
Polymorphonuclear leukocyte (PMNL) apoptosis is central to the successful resolution of inflammation. Since Somatic Cell Count (SCC) is an indicator of the mammary gland's immune status, this study sought to clarify the influence that these factors have on each other and on the evolution of the inflammatory process. Milk samples were stained with annexin-V, propidium iodide (PI), primary antibody antiCH138A. Negative correlation between SCC and PMNL apoptosis was found, and a statistical difference between high SCC group and low SCC group was observed concerning the rate of viable PMNL, apoptotic PMNL, necrotic PMNL and necrotic and/or apoptotic PMNL. Overall, the high cellularity group presented lower proportions of $\mathrm{CH} 138+$ cells undergoing apoptosis and higher proportions of viable and necrotic CH138+ cells. Thus, it can be concluded that PMNL apoptosis and SCC are related factors, and that in high SCC, milk apoptosis is delayed. Although there is a greater amount of active phagocytes in this situation, apoptosis' anti-inflammatory effects are decreased, while necrosis' proinflammatory effects are increased, which can contribute to chronic inflammation.
\end{abstract}

Keywords: apoptosis, CH138, flow cytometer, bovine, milk

Recebido em 15 de julho de 2011

Aceito em 10 de janeiro de 2012

*Autor para correspondência (corresponding author)

E-mail: dellalibera@usp.br 


\section{INTRODUÇÃ̃O}

A apoptose é um evento altamente regulado e caracteriza-se por fragmentação do DNA, condensação da cromatina, encolhimento da célula e formação de corpos apoptóticos (Thornberry 1998), além da externalização da fosfatidilserina. $O$ papel-chave da apoptose na resolução da inflamação se deve, entre outros fatores, ao fato de que nesse processo não ocorre extravasamento citoplasmático e consequente estimulação inflamatória, ao contrário do que ocorre no processo de morte por necrose (Sladek et al., 2006). O atraso desse fenômeno é, portanto, constantemente associado à cronificação da mastite (Boutet et al., 2004).

A necrose é um evento que pode ser desencadeado por dano físico ou biológico, e foi primeiramente diferenciada da apoptose por meio da análise de ultraestrutura de células sofrendo cada um desses tipos de morte celular (Keer et al., 1972). A necrose é caracterizada por inchaço mitocondrial, perda imediata da integridade da membrana e consequentes danos teciduais, enquanto a apoptose remove células redundantes e mantém a homeostase do tecido de forma segura e não imunogênica (Van Delft et al., 2010). É importante frisar que, apesar de o termo "morte celular programada" ter sido comumente associado à apoptose, estudos recentes têm proposto que, sob condições específicas, a necrose representa um processo regulado e bem orquestrado (Cho et al., 2010).

No contexto da manutenção da homeostase da glândula mamária, a morte celular, especificamente dos leucócitos polimorfonucleares (PMN), assume grande importância. Apesar de serem essenciais como primeira linha de defesa celular contra os patógenos da mastite (Piepers et al., 2009a), os PMN apresentam grande potencial de destruição do tecido glandular, seja pela secreção de mediadores inflamatórios ou pelo extravasamento citoplasmático decorrente da necrose. Como ocorre aumento da porcentagem desse tipo celular em até $90 \%$ (Koess e Hamann, 2008) durante a inflamação, a ocorrência da apoptose ou da necrose dos PMN pode intensificar, respectivamente, estímulos antiinflamatórios ou pró-inflamatórios de maneira muito intensa.
A migração de PMN para o lúmen da glândula mamária ocorre, pois essas células são atraídas por substâncias quimiotáxicas liberadas por células sentinelas na presença de um estímulo lesivo (Paape et al., 2003). Para exercerem suas funções, essas células realizam um processo denominado burst oxidativo, o qual resulta na geração de espécies reativas de oxigênio que contribuem para a morte de possíveis patógenos, mas que podem lesionar o próprio tecido mamário (Zhao e Lacasse, 2008). Dessa forma, não só a apoptose como também o subsequente clearance dos PMN por macrófagos são processos cruciais na resolução da inflamação (Sladek et al., 2005), e a desregulação desses processos provavelmente contribui na patogênese da doença inflamatória crônica (Rossi et al., 2007).

A apoptose dos PMN, por sua vez, não só previne um aumento da reação inflamatória, mas também representa um estímulo anti-inflamatório para as outras células (Fox et al., 2010). Um exemplo é a fagocitose de PMN apoptóticos por macrófagos, que, por meio da interação da fosfatidilserina exposta pelo PMN com um receptor no macrófago, estimula a secreção de TGF-beta e IL-10, que inibem a secreção de mediadores pró-inflamatórios como o TNF-alfa (Huynh et al., 2002). Outro exemplo é a capacidade dos neutrófilos em apoptose de se ligar a LPS, impedindo a estimulação dos leucócitos por essa mólecula sinal e, assim, impedindo uma intensificação da resposta inflamatória.

Por seu papel decisivo na manutenção, na diminuição ou no aumento do número de células envolvidas em um processo inflamatório, supõese no, presente estudo, que apoptose de PMN e a contagem de células somáticas (CCS) sejam fatores intimamente relacionados. A CCS é uma característica da saúde da glândula mamária, pois pode indicar inclusive a ocorrência de mastite subclínica (Brolund, 1985), além de estar associada com a alteração da qualidade das proteínas do leite, com mudanças na composição de ácidos graxos, lactose, concentrações de íons e minerais, aumento da atividade enzimática e pH aumentado no leite cru (Ogola et al., 2007).

Como a presença de PMN na mama está bem correlacionada ao aumento da CCS observado na mastite (Kelly et al., 2000), a apoptose desse tipo 
celular também poderia ser considerada um parâmetro de saúde da glândula mamária e um indicador da qualidade do leite. Dessa forma, o presente estudo objetiva estabelecer a correlação entre apoptose de PMN e CCS e comparar as taxas desse tipo de morte celular em um grupo com CCS elevada e em outro com CCS considerada basal, visando à melhor compreensão dos mecanismos de defesa e manutenção do equilíbrio celular da glândula mamária, sobretudo no que se relaciona à instalação da mastite.

\section{MATERIAL E MÉTODOS}

Foram colhidas 32 amostras de leite provenientes de oito vacas da raça Holandesa, sem antecedentes de mastite. As vacas foram distribuídas em dois grupos experimentais: o primeiro com baixa celularidade, <200.000 células/mL, e o segundo com alta celularidade, $>200.000$ células $/ \mathrm{mL}$, limite estabelecido de acordo com Schepers (1997).

Antes da colheita de leite, foi realizado o exame físico da glândula mamária. As amostras foram colhidas conforme as recomendações descritas no NMC (National..., 1999), Standards (1999), durante a ordenha da manhã, entre as 4 e as 7 horas e 30 minutos. Para as análises da celularidade (CCS automática), $40 \mathrm{~mL}$ de leite foram colhidos e encaminhados para a Clínica do Leite (Piracicaba - SP). Para a análise da morte celular, $200 \mathrm{~mL}$ de leite de cada quarto mamário foram colhidos juntamente com $200 \mathrm{~mL}$ de PBS em frascos com capacidade para $1.000 \mathrm{~mL}$ e foram encaminhados sob refrigeração ao Laboratório de Imunodiagnóstico, localizado na Faculdade de Medicina Veterinária e Zootecnia da Universidade de São Paulo. Em seguida, os tetos foram desinfetados com álcool $70 \%$ e os primeiros jatos foram desprezados. Aproximadamente $1 \mathrm{~mL}$ de leite foi colhido para o exame microbiológico.

Para a realização das provas de morte celular, as amostras de leite foram centrifugadas no laboratório em frascos com capacidade para $1.000 \mathrm{~mL}$ segundo as recomendações de Koess e Hamann (2008). Após três centrifugações, o botão celular foi ressuspendido em meio de cultura enriquecido (RPMI 1640) e submetido à avaliação da viabilidade pelo azul de Tripan. Após o ajuste celular para $2 \times 10^{6}$ células $/ \mathrm{mL}$, as amostras de leite foram avaliadas quanto à morte celular. O procedimento desta prova foi baseado no método descrito por Piepers et al. (2009b). Foram adicionados em todos os tubos $100 \mu \mathrm{L}$ da suspensão celular já ajustada e $1.000 \mu \mathrm{L}$ de tampão de ligação. Esse material foi centrifugado a $250 \mathrm{~g}$ a $4^{\circ} \mathrm{C}$, por oito minutos. O sobrenadante foi descartado, e o botão celular restante foi preservado e ressuspendido em $100 \mu \mathrm{L}$ do tampão de ligação. Adicionou-se anexina-V e incubou-se por 20 minutos à temperatura ambiente e no escuro, seguido de adição de $1.000 \mu \mathrm{L}$ de tampão de ligação aos tubos e nova centrifugação. Em seguida, o sobrenadante foi descartado e $100 \mu \mathrm{L}$ de tampão de ligação e $1 \mu \mathrm{L}$ de anticorpo primário CH138A (monoclonal mouse IgM anti-bovine CH138A; VMRD, Pullman, EUA, $\mathrm{n}^{\circ}$ cat. CH138A) foram adicionados. Após 30 minutos, $1 \mu \mathrm{L}$ do anticorpo secundário APC (goat anti-mouse IgM conjugado ao fluorocromo Allophycocyanin; Invitrogen, Carlsbad, EUA, $\mathrm{n}^{\circ}$ cat. M31505) foi adicionado e mantido por 30 minutos no escuro. Imediatamente antes da aquisição das amostras no citômetro de fluxo, $10 \mu \mathrm{L}$ de iodeto de propídeo (PI) foram adicionados.

Os dados foram obtidos pelo citômetro de fluxo FACS Calibur (Becton Dickinson Immunocytometry System, San Jose, CA, EUA) e analisados pelo Programa Flow Jo® versão 7.6.1. (Treestar - Versão 7.6.1 para Windows). Os leucócitos CH138+ foram identificados conforme as recomendações de Piepers et al. (2009b). As células consideradas em apoptose foram as células positivas para a anexina- $\mathrm{V}$ e negativas ao iodeto de propídio. As células consideradas em necrose foram as células positivas para o iodeto de propídio e negativas para a anexina. As células marcadas com os dois marcadores foram consideradas em necrose e/ou apoptose.

Para avaliação da morte celular, foi utilizado o programa Graphpad Instat - 1990 - 1993. (Statistical..., 1990). As amostras de cada grupo foram analisadas pelo teste de Kolgomorov e Smirnov para determinar se elas eram paramétricas ou não. Ficou determinado que as amostras de ambos os grupos não foram paramétricas. Assim, as amostras de cada grupo experimental foram submetidas ao teste não paramétrico de Mann-Whitney. Para a obtenção 
da correlação entre apoptose e CCS, foi utilizado o programa Microsoft Office Excel 2010.

\section{RESULTADOS}

Os estudos referentes à apoptose de neutrófilos na mama bovina limitam-se a outros países (Boutet et al., 2004; Sladek et al., 2005; Sladek et al., 2006; Piepers et al., 2009a; Piepers et al., 2009b ), sendo o presente estudo inédito no país. A correlação obtida entre $\log$ CCS e porcentagem de $\mathrm{CH} 138+$ em apoptose foi positiva para o grupo de baixa celularidade, negativa para o grupo de alta celularidade e também negativa para o conjunto total das amostras.
Os resultados obtidos durante a análise laboratorial das amostras foram sumarizados na Tab. 1. Na prova de fundo escuro realizada no momento da colheita, todas as amostras tiveram resultado negativo. No entanto, apesar de todas as amostras do grupo de CCS $<200.000$ células/mL apresentarem resultado negativo para o CMT, no grupo de CCS>200.000 células/mL, apenas $50 \%$ das amostras mostraram-se positivas. No exame microbiológico, 93,7\% das amostras do grupo de menor CCS tiveram resultado negativo, enquanto apenas $37,5 \%$ das amostras do grupo de maior CCS apresentaram esse resultado.

Tabela 1. Características analisadas nas amostras de leite de bovinos segundo os grupos de celularidade

\begin{tabular}{|c|c|c|c|}
\hline Característica & & Baixa celularidade & Alta celularidade \\
\hline \multirow{3}{*}{$\mathrm{CCS}$} & & 17312,5 & 1431000 \\
\hline & Média ( \pm DP) & $( \pm 23694,49655)$ & $( \pm 1475367,434)$ \\
\hline & Mediana & 13.000 & 916.000 \\
\hline \multirow{5}{*}{ CMT $(\%)$} & Traços & 0 & $12,5 \%$ \\
\hline & + & 0 & $31,25 \%$ \\
\hline & ++ & 0 & $6,25 \%$ \\
\hline & +++ & 0 & 0 \\
\hline & Negativas & $100 \%$ & $50 \%$ \\
\hline \multirow{2}{*}{ Exame microbiológico (\%) } & Positivas & $6,25 \%$ & $62,5 \%$ \\
\hline & Negativas & $93,75 \%$ & $37,5 \%$ \\
\hline \multirow[t]{2}{*}{$\%$ de leucócitos } & Min/Max & $48,50 / 96,00$ & $35,00 / 95,60$ \\
\hline & Mediana & $69,45 \mathrm{a}$ & $86,30 \mathrm{~b}(p=0,0365)$ \\
\hline \multirow[t]{2}{*}{ CH138+ / leucócitos (\%) } & Min/Max & $4,42 / 52,50$ & $6,72 / 68,10$ \\
\hline & Mediana & $11,50 \mathrm{a}$ & $33,20 \mathrm{~b}(p=0,0030)$ \\
\hline \multirow[t]{2}{*}{ Apoptose (\%) } & Min/Max & $2,24 / 54,00$ & $1,69 / 13,00$ \\
\hline & Mediana & $18,10 \mathrm{a}$ & $6,29 \mathrm{~b}(p=0,0026)$ \\
\hline \multirow[t]{2}{*}{ Apoptose e/ou necrose (\%) } & Min/Max & $6,13 / 51,00$ & $1,03 / 16,70$ \\
\hline & Mediana & $18,45 \mathrm{a}$ & $6,245 \mathrm{~b}(P<0,0001)$ \\
\hline \multirow[t]{2}{*}{ Necrose $(\%)$} & Min/Max & $5,64 / 45,40$ & $9,59 / 46,40$ \\
\hline & Mediana & $12,500 \mathrm{a}$ & $23,700 \mathrm{~b}(p=0,0426)$ \\
\hline \multirow[t]{2}{*}{ Viáveis (\%) } & Min/Max & $22,40 / 59,80$ & $44,10 / 76,30$ \\
\hline & Mediana & $34,10 \mathrm{a}$ & $61,10 \mathrm{~b}(P<0,0001)$ \\
\hline
\end{tabular}

Letras diferentes em uma mesma linha indicam diferenças entre valores. Baixa celularidade $=$ CCS $<200.000$ células $/ \mathrm{mL}(\mathrm{n}=16)$; Alta celularidade $=\mathrm{CCS}>200.000$ células $/ \mathrm{mL} \quad(\mathrm{n}=16) ; \mathrm{DP}=$ desvio-padrão; $\mathrm{CMT}=$ California Mastitis Test.

A análise da população de leucócitos nos dois grupos experimentais, desconsiderando os debris celulares, foi realizada por meio do teste de Mann-Whitney. O valor de $\mathrm{p}$ encontrado foi 0.0365, considerado significante, levando à conclusão de que há diferença estatística na porcentagem de leucócitos na população entre os grupos experimentais, sendo que, conforme o esperado, o valor da mediana encontrada para o grupo de CCS> 200.000 células/mL foi maior do que aquele encontrado para o grupo de menor CCS. 
De maneira semelhante, observou-se diferença estatística na porcentagem de $\mathrm{CH} 138+$ entre os grupos $(\mathrm{P}<0,003)$, considerada altamente significativa. A mediana da população de CH138+ encontrada no grupo de mais elevada CCS foi maior do que aquela encontrada para o grupo de mais baixa CCS.

Quantificou-se também a viabilidade da população $\mathrm{CH} 138+$, diferenciando-se as células em apoptose, necrose, necrose e/ou apoptose e células viáveis, de modo que os valores de $\mathrm{P}$ encontrados foram, respectivamente, 0.0026, $0.0426,<0.0001$ e $<0.0001$ para cada uma dessas populações. Tais valores foram considerados significativos, o que indica que há diferença entre as porcentagens de $\mathrm{CH} 138+$ em apoptose, necrose, necrose e/ou apoptose e CH138+ viáveis entre o grupo de maior CCS e o grupo de menor CCS. Foi observado que as medianas encontradas para $\mathrm{CH} 138+$ em apoptose e para $\mathrm{CH} 138+$ em necrose e/ou apoptose foram maiores nos grupos de menor CCS, enquanto as medianas encontradas para $\mathrm{CH} 138+$ viáveis e para aqueles em necrose foram maiores para $o$ grupo de maior CCS.

\section{DISCUSSÃO}

Os resultados obtidos no presente estudo fortalecem a hipótese de que morte celular, CCS e saúde da glândula mamária são conceitos diretamente relacionados. Com o intuito de comparar as taxas de apoptose no leite de vacas sadias com o leite de vacas com CCS elevada, estratificaram-se as amostras em dois grupos, tendo como base um parâmetro de produção. Apesar de a apoptose de neutrófilos em humanos já ter sido alvo de pesquisas no país, nenhum estudo focou o neutrófilo bovino, sendo a associação deste fenômeno com a CCS um importante parâmetro de produção igualmente inédito.

Os grupos foram compostos por amostras com alta celularidade e baixa celularidade, considerando que, segundo Schepers (1997), o limite de 200.000 células $/ \mathrm{mL}$ representa um valor adequado para a caracterização de quartos como infectados ou não, sendo a sensibilidade do diagnóstico $75 \%$, e a especificidade $90 \%$. Segundo Schukken (2003), o valor de 200.000 células/mL não representa um valor fisiológico que distingue quartos saudáveis de quartos mastíticos, mas sim um valor operacional e prático a ser utilizado no campo de modo a minimizar erros de diagnóstico. Dessa forma, apesar de as variáveis fase da lactação, idade e número de partos serem importantes influências na CCS de um quarto mamário (Kelly et al., 2000), a estratificação e a caracterização dos grupos no presente estudo foram feitas independentemente destas variáveis, tendo como parâmetro o valor prático de 200.000 células $/ \mathrm{mL}$.

$\mathrm{O}$ alto custo da técnica envolvida limita o número de amostras utilizadas, o que se repete em outros estudos similares realizados em outros países (Sladek et al., 2005; Sladek et al., 2006; Piepers et al., 2009b). No presente estudo, a análise estatística realizada apontou diferença entre os dois grupos para todos os parâmetros celulares avaliados, além da existência de uma correlação entre apoptose de PMN e CCS dentro de cada grupo.

Quanto ao principal evento analisado, a apoptose de PMN, foi observada maior porcentagem de $\mathrm{CH} 138+$ em apoptose no grupo de baixa celularidade. Tal resultado pode ser explicado por duas hipóteses, sendo a primeira delas relacionada à inibição da apoptose de PMN em mamas com alta CCS, e a segunda a um efeito diluidor da necrose sobre a apoptose em mamas inflamadas e/ou hipoteticamente infectadas. A primeira hipótese proposta relaciona-se à inibição direta da apoptose, que pode refletir em diminuição absoluta do fenômeno, independentemente de maior ou menor ocorrência de outros tipos de morte celular. $\mathrm{O}$ mesmo fato não ocorre no segundo cenário sugerido, no qual a diminuição da apoptose é relativa, já que é influenciada pelo aumento da necrose, diminuindo o percentual de $\mathrm{CH} 138+$ observado em apoptose.

Considerando-se a taxa de apoptose de mamas sadias como um limite basal, a primeira hipótese elaborada é condizente com uma suposição feita por Boutet et al. (2004), que consiste na inibição da apoptose dos PMN em mamas com mastite subclínica, situação em que a CCS é caracteristicamente alta. Essa inibição, segundo o autor, é causada por um fator denominado granulocyte-macrophage colonystimulating factor (GMCSF), o qual é secretado por leucócitos proporcionalmente ao aumento da CCS. O GMCSF, de acordo com Boutet et al. 
(2004), age por meio da ativação da proteína STAT5, a qual aumenta a transcrição de Bcl-xl, uma proteína antiapoptótica da famíla $\mathrm{Bcl}-2$, inibindo principalmente a via intrínseca da apoptose. Já Sladek et al. (2006), que encontraram menores taxas de PMN em apoptose após inoculação de Streptococcus uberis em mamas virgens, atribuíram tal resultado, em parte, a uma possível ação anti-apoptótica de certos mediadores anti-inflamatórios como o IL1- beta.

Boutet et al. (2004) apontam essa possível inibição da apoptose como um fator que colabora com a inflamação crônica da mama, já que tanto a interação das células apoptóticas com outras células quanto os efeitos anti-inflamatórios desse processo tornam-se limitados pelo menor número de células em apoptose. Sobre essa relação entre inibição da apoptose e cronificação do processo inflamatório, Piepers et al. (2009a) fizeram uma consideração importante, apontando que, nos primeiros estágios da infecção intramamária, o atraso na apoptose pode aumentar o potencial de fagocitose da defesa mamária. A proposição de Piepers et al. (2009a) é fortalecida quando se observa a porcentagem de PMN viáveis encontrada no presente estudo, que foi maior no grupo de alta celularidade. Desta forma, a maior mobilização de células se comprovou não apenas pelo aumento numérico, mas também pela maior taxa de viabilidade. Tais valores estão de acordo com aqueles encontrados por Koess e Hamann (2008) no que diz respeito a um aumento da viabilidade de PMN de um grupo de menor CCS para outro de maior CCS.

A segunda hipótese estabelecida se refere a um aumento da morte celular por necrose em detrimento da apoptose. Sendo as taxas de apoptose menores e as de necrose maiores no grupo de CCS elevada, pode ter ocorrido um efeito diluidor da necrose, diminuindo o percentual de células observadas em apoptose. Pode-se supor também a ocorrência de um fenômeno denominado necrose secundária, citada por Zhao e Lacasse (2008), que consiste na necrose de corpos apoptóticos que demoraram para ser fagocitados por macrófagos e removidos do sítio inflamado. Esse evento pode estar colaborando para o aumento da necrose observado no presente estudo.
O grupo experimental de baixa celularidade pode ser considerado como representativo de uma situação basal da glândula mamária, tendo em vista que os testes microbiológico e CMT tiveram, respectivamente, $93,7 \%$ e $100 \%$ de resultados negativos. $O$ grupo de alta celularidade não deve ser associado à única situação fisiológica da mama, já que o limite de 200.000 células $/ \mathrm{mL}$ utilizado representa um valor prático de uso a campo.

As mudanças observadas na apoptose de PMN durante o presente estudo devem ser analisadas levando-se em consideração os diferentes efeitos que a modulação da apoptose pode causar à homeostase da glândula mamária. Segundo Sladek et al. (2005), se a apoptose for aumentada, apesar de enfraquecer o potencial de defesa por fagocitose da mama, favorece a resolução da inflamação; e se for atrasada, pode beneficiar o acúmulo de neutrófilos ativos na mama, mas pode também favorecer a instalação de um processo inflamatório crônico. Assim, não é possível caracterizar o atraso da apoptose de PMN observado no presente estudo como algo puramente negativo, já que, apesar dos efeitos lesivos e pró-inflamatórios que o extravasamento citoplasmático das células acumuladas no úbere pode causar, essas células podem agir em defesa da mama por mais tempo.

\section{CONCLUSÕES}

As taxas de apoptose de PMN diferem entre mamas com alta e com baixa celularidade. Assim, infere-se que, durante a mastite, aumentos na celularidade do leite estão associados à diminuição absoluta e relativa da apoptose de neutrófilos, bem como a um aumento da morte por necrose destes. Apesar de não ser possível estabelecer uma relação de causa e consequência entre o atraso na apoptose de PMN e CCS elevada, conclui-se que esses fatores se influenciam e que, assim, influenciam também a saúde da glândula mamária e a qualidade do leite. No que diz respeito à evolução de processos inflamatórios em geral, o conhecimento sobre a dinâmica da modulação da apoptose de PMN pode colaborar para maior compreensão dos processos de cronificação e resolução da inflamação, sendo necessários mais estudos para estabelecer quais são os limites entre benefício e prejuízo causados pela estimulação ou pelo atraso da apoptose de PMN. 


\section{AGRADECIMENTOS}

À Fundação de Amparo à Pesquisa do Estado de São Paulo (FAPESP), pelo apoio financeiro que possibilitou a realização desse projeto (processo FAPESP 2009/50672).

\section{REFERÊNCIAS}

BOUTET, P.; BOULANGER, D.; GILLET, L. et al. Delayed neutrophil apoptosis in bovine subclinical mastitis. J. Dairy Sci., v.87, p.4104-4114, 2004.

BROLUND, L. Cell counts in bovine milk. Acta Vet. Scand., v.80, p.155-123, 1985.

CHO, Y.S.; PARK, S.Y.; SHIN, H.S.; CHAN, F.K. Physiological Consequences of Programmed Necrosis, an Alternative form of Cell Demise. Mol. Cells., v.29, p.327-332, 2010.

FOX, S.; LEITCH, A.; DUFFIN, R.; HASLETT, C. et al. Neutrophil apoptosis: relevance to the innate immune response and inflammatory disease. J. Innate Immun., v.2, p.216-227, 2010.

HUYNH, M.L.; FADOK, V.A.; HENSON, P.M. Phosphatidylserine-dependent ingestion of apoptotic cells promotes TGF-beta1 secretion and the resolution of inflammation. J. Clin. Invest., v.109, p.41-50, 2002.

KELLY, A.L.; TIERNAN, D.; O'SULLIVAN, C.; JOYCE, P. Correlation between bovine milk somatic cell count and polymorphonuclear leukocyte level for samples of bulk milk and milk from individual cows. J. Dairy Sci., v.83, p.300-304, 2000.

KERR, J.F.R.; WYLLIE, A.H.; CURRIE, A.R. Apoptosis: basic biological phenomenon with wideranging implications in tissue kinetics. $\mathrm{Br}$. J. Cancer, v.26, p.239-257, 1972.

KOESS, C.; HAMANN, J. Detection of mastitis in the bovine mammary gland by flow cytometry at early stages. J. Dairy Res., v.75, p.225-232, 2008.

NATIONAL mastitis council. Laboratory Handbook on Bovine Mastitis. Madison WI, USA: USA National Mastitis Council, 1999.

OGOLA, H.; SHITANDI, A.; NANUA, J. Effect of mastitis on raw milk compositional quality. J. Vet. Sci., v.8, p.237-242, 2007.
PAAPE, M.J.; BANNERMAN, D.D.; ZHAO, X.; LEE, J. The bovine neutrophil: Structure and function in blood and milk. Vet. Res., v.34, p.597-627, 2003.

PIEPERS, S.; OPSOMER, G.; MEYER, E.; DEMEYERE, K. et al. Heifer and quarter characteristics associated with periparturient blood and milk neutrophil apoptosis in healthy heifers and in heifers with subclinical mastitis J. Dairy Sci., v.92, p.4330-4339, 2009a.

PIEPERS, S.; DE VLIEGHER, S.; DEMEYERE, K. et al. Technical note: Flow cytometric identification of bovine milk neutrophils and simultaneous quantification of their viability. J. Dairy Sci., v.92, p.626-631, 2009b.

ROSSI, A.G.; HALLETT, J.M.; SAWATZKY, D.A. et al. Modulation of granulocyte apoptosis can influence the resolution of inflammation. Biochem Soc Trans. v.35, p.288-291, 2007.

SCHEPERS, A.J.; LAM, T.J.; SCHUKKEN, Y.H. et $a l$. Estimation of variance components for somatic cell counts to determine thresholds for uninfected quarters, J. Dairy Sci., v.80, p.1833-1840, 1997.

SCHUKKEN, Y.H.; WILSON, D.J.; WELCOME, F. et al. Monitoring udder health and milk quality using somatic cell counts. Vet. Res., v.34, p.579-596, 2003.

SLADEK, Z.; RYSANEK, C.; RYZNARNOVA, H.; FALDYNA, M. Neutrophil apoptosis during experimentally induced Staphylococcus aureus mastitis. Vet. Res., v.36, p.629-643, 2005.

SLADEK, Z.; RYSANEK, C.; RYZNARNOVA, H.; FALDYNA, M. The role of neutrophil apoptosis during experimentally induced Streptococcus uberis mastitis. Vet. Med. v.51, p.437-447, 2006.

STATISTICAL Analysis Systems for Personal Computers, 1990-93: Graphpad Instat software.

THORNBERRY, N.A. Caspases: Enemies Within. Science. v.281, p.1312-1316. 1998.

AN DELFT, M.F.; SMITH, D.P.; LAHOUD, M.H. et al. Apoptosis and non-inflammatory phagocytosis can be induced by mitochondrial damage without caspases. Cell Death Differ, v.17, p.821-832, 2010.

ZHAO, X.; LACASSE, P. Mammary tissue damage during bovine mastitis: Causes and control. J. Anim. Sci, v.86, p.57-65, 2008. 